\title{
SEMINAR ON THE INTERNATIONAL AFFAIRS OF THE RED CROSS
}

The Henry Dunant Institute organized a Seminar on the International Affairs of the Red Cross from 9 to 13 September 1974, in Geneva. Fourteen leaders of National Red Cross and Red Crescent Societies took part, from Bangladesh, Denmark, Fiji, Jordan, Kuwait, Sweden, Tanzania, Trinidad and Tobago, United Kingdom, Uganda and the Republic of Vietnam.

The purpose of the Seminar, held in response to requests from several Presidents of National Societies, was to provide an introduction, at a high level, to the international affairs of the Red Cross movement as a whole. The Red Cross demands much from all of its leaders, but still more from those who have the opportunity to serve it in the international sphere. A knowledge, however comprehensive, of one National Society is not sufficient : effective participation in the international work of the movement requires a wider knowledge, the acquisition of which has hitherto been a difficult, usually lengthy and often haphazard process.

The Seminar, the first of its kind, was therefore designed to explore systematically, with extensive opportunities for discussion, three main subject areas :

1. Structure and tasks of the Red Cross: Historical evolution, Red Cross principles, organization and work of the Geneva institutions, relations between the National Societies and Geneva, relations between the Red Cross and other international organizations. 
2. International humanitarian law: The underlying ideas, the Geneva Conventions, current tendencies in the development of the law of armed conflict.

3. Red Cross international meetings: the different types of meetings and their purpose, the role and work of a delegation, how to use simultaneous interpretation.

The faculty for the Seminar totalling sixteen persons was drawn from the International Committee of the Red Cross and the League of Red Cross Societies as well as from the academic world. Most of the sessions took place at the Henry Dunant Institute's new premises, while others were held at the ICRC and at the League.

At the close of the Seminar, the participants expressed the hope that the Institute would continue to organize seminars of this type and made a number of suggestions for improvements, one of which was that greater emphasis should be placed on the practical work of the Geneva institutions, with better opportunities to witness them in action.

The Seminar was held in English. A second Seminar, in French, is planned for next year and it will have the benefit of the experience gained on this first occasion.

\section{A SYMPOSIUM AT THE HENRY DUNANT INSTITUTE}

From 14 to 16 October 1974, a symposium entitled "The health care cost explosion: Which way now?" was held at the Henry Dunant Institute, in Geneva. The symposium-which was organized with the help of a grant from Pharma Information of Baslewas a fresh attempt to get to grips with the problem of dramatic increases in the costs of health care, which in most countries are absorbing an ever-increasing share of national resources. This problem troubles governments, citizens as patients and as taxpayers, 